\title{
CARTOGRAFIA TEMÁTICA: POTENCIALIDADES E LIMITES DO BAIXIO DO VIADUTO ALCÂNTARA MACHADO
}

\author{
Victor Martins de Aguiar \\ Universidade do Oeste Paulista - UNOESTE, Curso de Arquitetura e Urbanismo, Presidente Prudente, SP. E- \\ mail: victoraguiar@unoeste.br
}

\section{RESUMO}

Ao analisar os usos e as ocupações no baixio do viaduto Alcântara Machado, em São Paulo, este trabalho procura mostrar, através de uma cartografia temática, a complexidade deste território que, justamente por ser intersticial, constitui-se como oportunidade para atuações espontâneas promovidas por atores sociais. Ao inserir e manter iniciativas no baixio, esses atores conseguiram estabelecer ali espaços públicos. A literatura acadêmica tem demonstrado que a apropriação do espaço público pode gerar um senso de coletividade a partir de sua gestão, caso ela seja compartilhada. No entanto, as leituras etnográficas realizadas no baixio do viaduto Alcântara Machado revelam que, embora as atuações dos atores sociais apresentam efeitos positivos, a gestão desses espaços públicos são introjetadas em tais personagens, ou seja, os usuários pouco participam das decisões.

Palavras-chave: baixio de viaduto; espaço residual; espaço público; cartografia temática.

\section{THEMATIC CARTOGRAPHY: POTENTIALITY AND LIMITS IN THE AREAS BELLOW ALCÂNTARA MACHADO VIADUCT}

\begin{abstract}
In analyzing the uses and occupations in the areas bellow Alcântara Machado viaduct, in São Paulo, this work seeks to show, through a thematic cartography, the complexity of these portions of the municipality territory which, for the very reason of being interstitial, became opportunities for spontaneous actions and projects developed by different social stakeholders. By introducing and maintaining initiatives in these "baixios" these social stakeholders were able to stablish public spaces on them. The academic literature has demonstrated that this kind of appropriation of common but non-used space in the city can generate a sense of community deriving from its management, provided it is performed in a collective manner. However, the ethnographic readings carried the areas bellow Alcântara Machado viaduct reveal that, although the actions of social actors have positive effects, the management of these public spaces are introjected in such characters, that is, users do not participate in decisions.
\end{abstract}

Keywords: under viaduct; residual space; public space; thematic cartography. 


\section{INTRODUÇÃO}

É consenso entre urbanistas e pesquisadores que, em grande parte do século 20 , as intervenções públicas em São Paulo buscaram resolver, sobretudo, as demandas de transporte individual. Como efeito desse "urbanismo rodoviarista", implantaram-se ações desestruturadoras do tecido urbano, com a produção de efeitos negativos como expansões desnecessárias da malha urbana, construção aleatória e muitas vezes inadequada do sistema viário, ocupando os fundos de vale e impermeabilizando várzeas (GROSTEIN, 2010).

Enquanto os automóveis circulavam pela cidade, os espaços resultantes da implantação dessas estruturas foram historicamente tratados pelos estudos urbanos como territórios do abandono e passaram a ser identificados como locais de uma resistência solitária, onde a cidadania não plena se abriga (AGUIAR, 2017). A maior parte dos estudos trata os baixios de viadutos como espaços "residuais", "vazios", "marginais". Lugares onde a exclusão se expressa e onde se tornam visíveis as contradições sociais não resolvidas da metrópole.

Ao analisar os usos geridos pelos atores sociais no viaduto Alcântara Machado, o trabalho busca ressaltar as características e as complexidades dos espaços públicos ali existentes. Tendo em vista, que entender as potencialidades e limites dos novos atores e de seus papéis no urbanismo, esclarecendo quem são esses atores, o que os motiva e os benefícios de suas propostas, pode se revelar uma ferramenta particularmente útil para administradores e funcionários do poder público e de outras instituições com atuação na cidade.

\section{METODOLOGIA}

O desenvolvimento deste trabalho se deu através de consultas em fontes de dados secundárias, como livros, artigos e sites da Internet, com o intuito de compor o embasamento teórico sobre: baixio de viaduto, espaço público e cartografia temática.

A partir de leituras etnográficas ${ }^{1}$ no baixio do viaduto Alcântara Machado em dias e horários diferentes, também buscou-se compreender o que levou às ocupações, as características dos lugares em que elas ocorrem, qual é a percepção e a ligação dos usuários com cada um dos projetos dos atores sociais. Estas informações foram sistematizadas através de uma cartografia temática ${ }^{2}$ com a intenção de evidenciar o que não é visível, mas ocupa um espaço estigmatizado como abandonado na cidade.

\section{DISCUSSÃO}

O viaduto Alcântara Machado tem 1.125 m de extensão e está localizado na avenida de mesmo nome, entre os bairros do Brás e da Mooca, em São Paulo. Durante a construção, a estrutura erguida para transpor a estrada de ferro Santos-Jundiaí foi considerada o maior viaduto urbano do país ${ }^{3}$.

\footnotetext{
${ }^{1}$ Winkin $(1998$, p. 132) destaca que as leituras etnográficas exigem do pesquisador três competências: arte de ver; arte de ser; arte de escrever. Também se deve ter a preocupação de ir-e-voltar no espaço objeto de estudo e de que as observações ali realizadas possam ser sistematizadas, por exemplo, através de mapas temporais.

${ }^{2}$ Romagnoli $(2009$, p. 169) afirma que a cartografia é um modo de conceber a pesquisa e o encontro do pesquisador com seu campo. De forma, que pode ser compreendida como método, como outra possibilidade de conhecer a partir das percepções, sensações e afetos vividos no seu campo de estudo.

${ }^{3}$ Convite de inauguração. Estado de São Paulo, São Paulo, 17 maio 1967. Primeiro Caderno, p. 5.
} 
De maneira geral, nota-se que inicialmente o baixio do viaduto tinha um uso público a partir de uma feira livre ${ }^{4}$. Com a desativação da feira, no final da década de 1980, o baixio foi ocupado progressivamente pela população em situação de rua ${ }^{5}$. 0 vazio que se originou no baixio com o desmonte da feira foi entendido pelos ocupantes não mais como um espaço público, mas como uma propriedade privada para a construção de moradia própria por diferentes famílias.

Após a retirada das famílias do viaduto, em 2002, a prefeitura concedeu o espaço para a CET (Companhia de Engenharia de Tráfego) instalar um depósito de veículos ${ }^{6}$. A medida, que tinha como objetivo evitar a ocupação do local por novos moradores de rua, não foi eficaz em sua intenção: pessoas passaram a viver entre os veículos.

É com a academia de boxe de Nilson Garrido, instalada em 2006, que um dos trechos do baixio do viaduto (próximo à linha férrea) passou a ser usado novamente pela população, adquirindo de certa forma o estatuto de espaço público.

Depois de a academia de boxe do Garrido ter se instalado no baixio, em 2008, o prefeito Gilberto Kassab inaugurou um conjunto de equipamentos esportivos ali, atendendo as reivindicações de moradores do bairro de que o espaço fosse usado para o lazer dos que residiam no entorno. Mas a ação municipal também teve como objetivo recuperar uma parte do espaço usado pela CET, ocupada por moradores de rua.

No mesmo ano, em 2008, Fátima, moradora do bairro há mais de 50 anos, com o receio de que novamente a população de rua voltasse a viver no viaduto, assumiu a gestão dos equipamentos esportivos e instituiu, por volta de 2010, a Associação Esportiva, Social, Cultural Futuro Melhor da Mooca. A entidade tem como sede a área poliesportiva do viaduto. O encargo principal de Fátima, a "zeladora do viaduto", é captar recursos para a manutenção da área. A forma encontrada por ela para fazer isso foi passar a alugar duas das quatro quadras, as com grama sintética.

O baixio do viaduto Alcântara Machado ampliou seu caráter de área para práticas esportivas quando uma academia destinada à realização de atividades físicas por idosos foi implantada ali pelo poder público em 2012. Em 2012, a prefeitura também instalou um espaço de convivência conhecido como "Tenda"7 no trecho restante do baixio. Nela, os moradores de rua poderiam lavar roupas, tomar banho, receber auxílio psicológico e fazer cursos e artesanatos.

O espaço era gerido pelo Instituto Social Santa Lúcia, entidade terceirizada contratada pela prefeitura que já administrava outras Tendas, como a do viaduto Bresser. No entanto, a partir de 2013, problemas estruturais na gestão da Tenda acarretaram a ocupação da academia dos idosos e de seu espaço pelos moradores de rua.

Ao se caminhar nas calçadas, entre 2015 e 2016, foi possível observar os moradores de rua conversando na entrada de suas moradias, estendendo roupas nos alambrados, assistindo televisão ou ouvindo rádio graças à eletricidade obtida de "gatos" na fiação.

A partir desse quadro, ao final de 2016, a percepção do baixio do viaduto Alcântara Machado entre a população da cidade era a de um lugar degradado, principalmente por causa da ocupação da população em situação de rua e dos resíduos que ela gera. Devido à presença do projeto de Garrido e da área poliesportiva gerida por Fátima, para algumas pessoas o baixo é percebido como espaço de lazer e de caráter público. As características e

\footnotetext{
${ }^{4}$ Faria abre feira nova. Estado de São Paulo, São Paulo, 20 jun. 1968. Primeiro Caderno, p. 10

${ }^{5}$ Informação obtida com moradores do bairro em 13 de setembro de 2015.

${ }^{6}$ ALENCAR, Izidoro. SP paga caro para ter "guincho de luxo". Folha de São Paulo, São Paulo, 7 abr. 2002. Cotidiano, p. 1.

${ }^{7}$ Gestão Haddad fecha espaços para moradores de rua. Folha de São Paulo, São Paulo, 6 ago. 2014. Cotidiano, p. 6.
} 
os limites para uma gestão compartilhada desses espaços públicos foram aprofundados neste trabalho.

\section{RESULTADOS}

Os espaços da academia de boxe de Nilson Garrido $^{8}$ foram construídos em alvenaria e se percebe que foram erguidos em momentos diferentes, sem um projeto para a área toda, mas conforme a necessidade. Os banheiros dos alunos, a área de dormir e a cozinha dos moradores ficam no fundo da academia (Figura 1).

Figura 1. Cartograma da disposição dos usos da academia de boxe no baixio do viaduto Alcântara Machado.
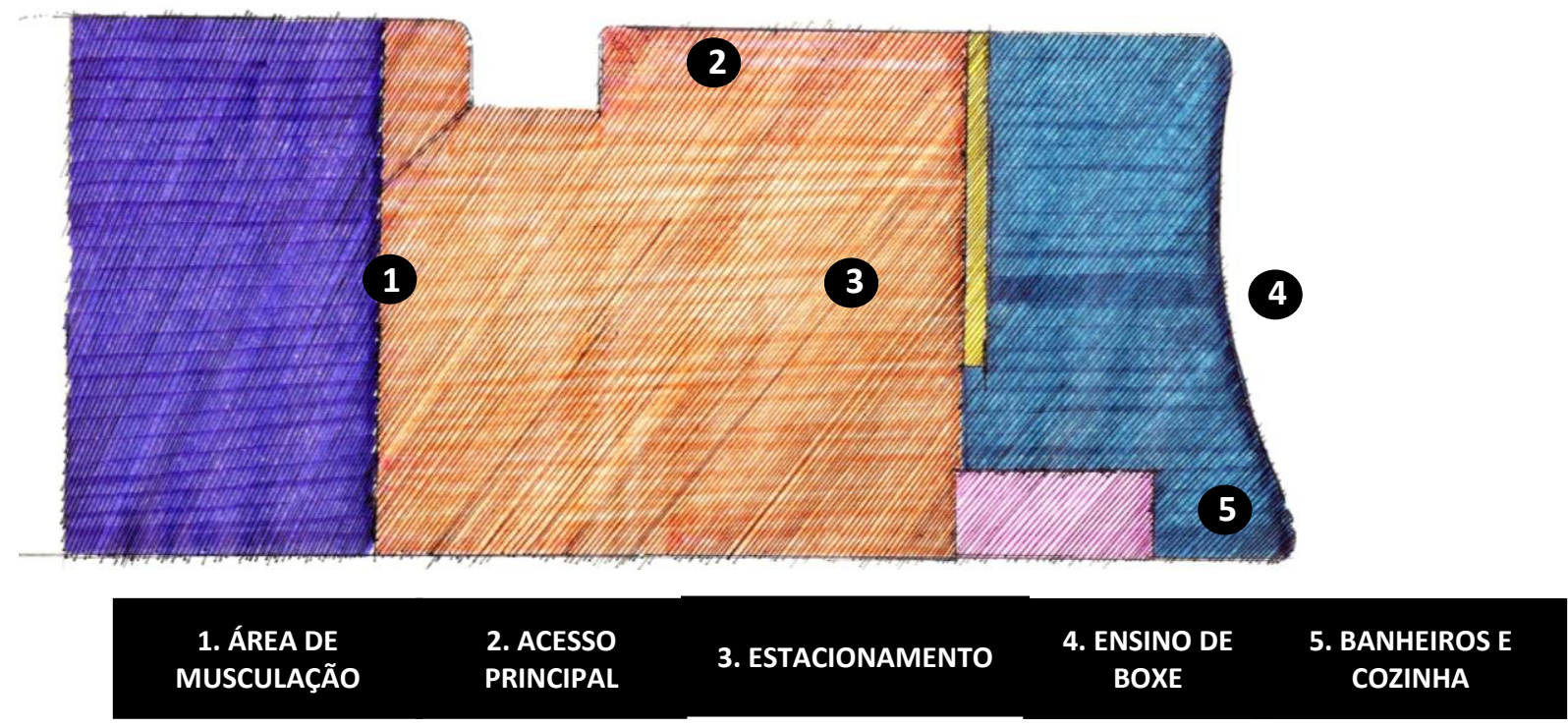

Fonte: Arquivo do autor, 2016.

Ao acompanhar as atividades no espaço em diferentes períodos do dia, percebe-se que os usuários normalmente chegam, malham e logo vão embora. Esse tempo de permanência no espaço é um pouco maior do que uma hora e boa parte dos usuários fica nos aparelhos de musculação (Figura 2).

\footnotetext{
${ }^{8}$ Foram realizadas, de agosto de 2015 a novembro de 2016, 12 visitas ao espaço. 
Figura 2. Cartograma do uso da academia de boxe no dia 22 de agosto de 2016 às $14 \mathrm{~h}$.

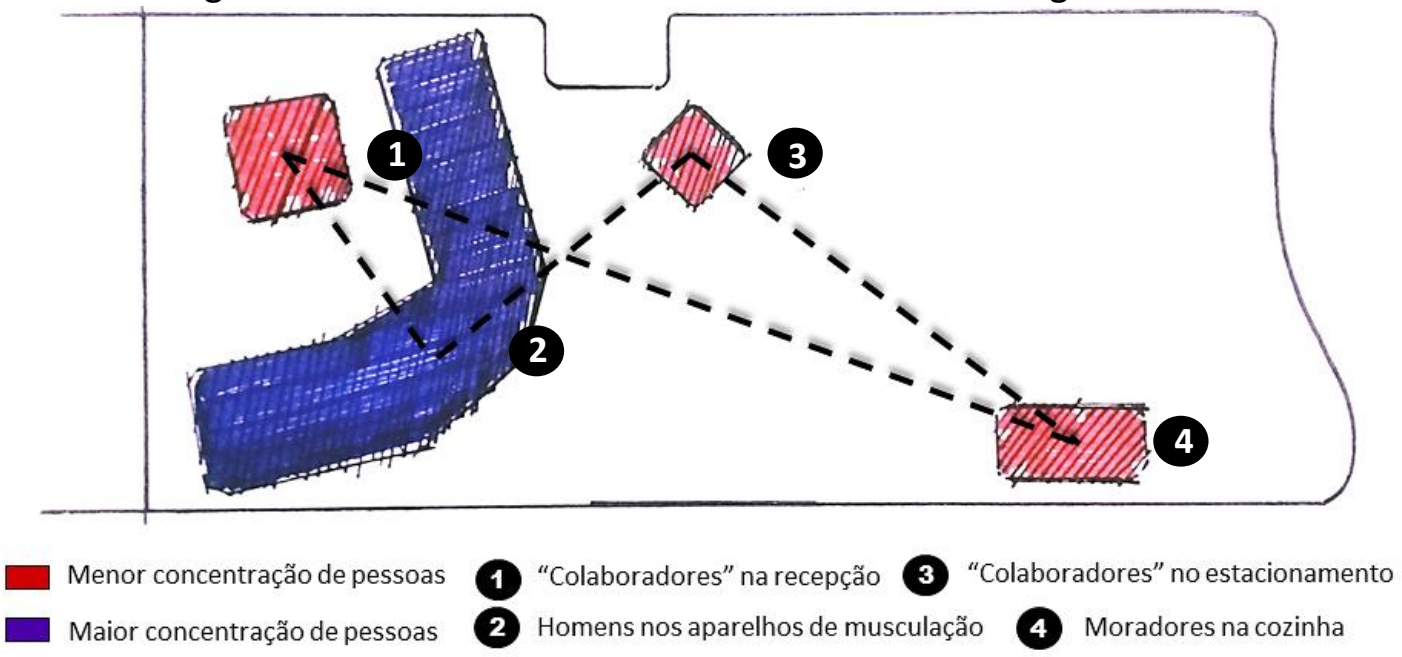

Fonte: Arquivo do autor, 2016.

O que motiva grande parte das pessoas a começar a frequentar o espaço é o cuidado com o corpo. Com o passar do tempo, no entanto, com a convivência com os demais usuários e conhecendo melhor o trabalho realizado por Garrido, a percepção tende a mudar e apoia-se o projeto como ação social. O motivo para frequentar o projeto pode, para alguns usuários, envolver interesses financeiros, como a busca por uma oportunidade de trabalho, pois o espaço reúne seguranças de empresas próximas que avisam quando há vaga.

A partir também das visitas ao espaço percebe-se que os aparelhos de musculação são manuseados principalmente por homens. Os usuários mais jovens, de 18 e 25 anos, costumam se vestir como se estivessem em uma academia particular e utilizam equipamentos como luvas e cinturões (Figuras 3 e 4). Chegam com roupas esportivas e fones de ouvido, e se dirigem diretamente para os aparelhos, dando preferência aos que estão distantes de outro em uso, o que sugere que evitam contato com os demais usuários.

Figuras 3 e 4. A presença de homens é dominante nos diferentes horários de funcionamento do projeto.


Fonte: Arquivo do autor, 2016 
Os mais velhos, de 30 a 45 anos, sempre conversam sobre a maneira de obter melhores ganhos na série dos exercícios. Entre eles, muitos chegam ao espaço de carro ou de moto e cumprimentam os "responsáveis" pela manutenção da academia na recepção. Os aparelhos mais procurados são para os braços e o peito. Alguns treinam de calça jeans e até de chinelo, poucos vestem roupas esportivas.

De maneira geral, os usuários participam pouco da manutenção diária. A contribuição deles se resume à colaboração financeira ${ }^{9}$, quando ela ocorre. É Garrido quem centraliza toda a gestão, e não existe com os usuários um diálogo visando fortalecer a participação coletiva e outras frentes de trabalho do projeto.

Como a gestão do espaço está toda centrada em Garrido, cabe questionar em que medida a academia constitui um espaço público e qual seria sua contribuição para a discussão sobre o uso dos espaços residuais dos baixios de viadutos a partir de um senso de coletividade, conforme também foi observado na área poliesportiva.

Desde 2011, aos sábados, na área poliesportiva ${ }^{10}$ um grupo de imigrantes bolivianos aluga duas das quadras existentes e joga futebol enquanto as mulheres assistem em companhia dos filhos. Esse grupo tem grande entrosamento com o espaço (Figura 5). Nos jogos sempre há uma torcida, e eles levam alimentos típicos para consumir ao final das partidas, o que resulta em uma pequena festa, mas restrita àquela comunidade.

Figura 5. Cartograma da disposição dos usos na área poliesportiva no baixio do viaduto Alcântara Machado.

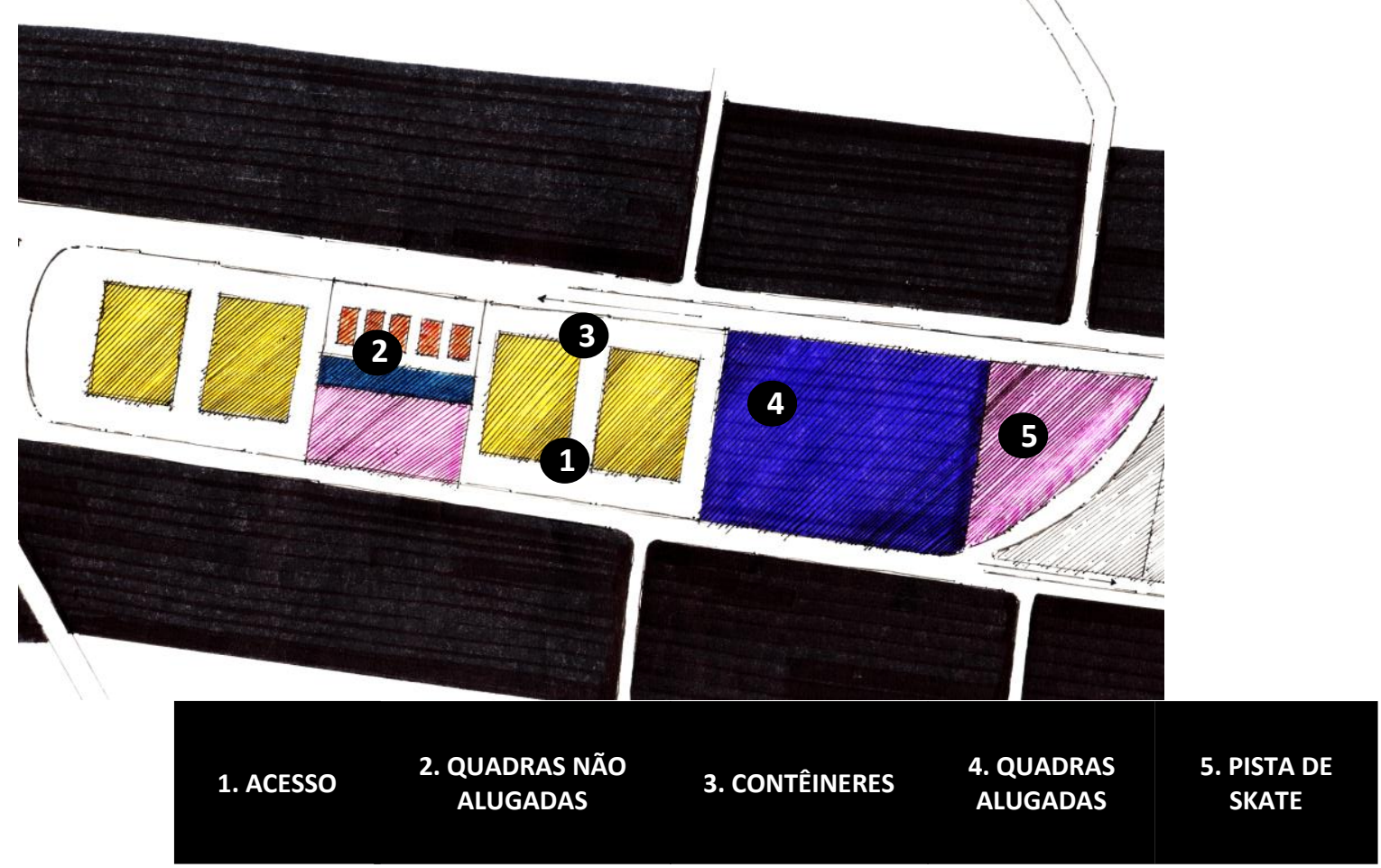

Fonte: Arquivo do autor, 2016.

\footnotetext{
${ }^{9}$ A colaboração mensal é no valor de R\$ 20, mas não é algo imposto: ajuda quem têm condições.

${ }^{10}$ Foram realizadas, de maio de 2015 a novembro de 2016, 15 visitas ao espaço.
} 
Durante a semana no espaço observei um grupo de amigos à tarde ${ }^{11}$, com faixa etária entre 20 a 40 anos, moradores da Zona Leste. Eles costumam chegar de carro ou de bicicleta. Ao final das partidas, era comum ligarem o som dos carros em volume alto. Conversavam entre as mesas de concreto enquanto bebiam cervejas trazidas em coolers. Durante os jogos, todos usavam equipamentos como meiões, caneleiras e chuteiras, diferente de outros grupos.

Os amigos combinavam os jogos por meio de um grupo de mais de 30 pessoas no aplicativo WhatsApp. Nem todos vinham toda semana. Para usar a quadra quatro vezes ao mês, combinaram com Fátima que pagariam $R \$ 200$, valor dividido entre eles.

Outro grupo encontrado foi o dos amigos que estudaram juntos e moravam no bairro do Glicério. Eles também usavam as redes sociais para marcar os jogos. $O$ grupo era formado por 12 rapazes de 18 a 25 anos (Figura 6). Quando estiveram na quadra, trouxeram água gelada e equipamentos esportivos. Como no espaço não há bebedouros, a maioria dos usuários traz água; alguns recorrem a uma torneira próxima das quadras, que algumas pessoas usam para se refrescar nos dias mais quentes.

Figura 6. As partidas realizadas por diferentes grupos de amigos normalmente ocorrem uma vez na semana.

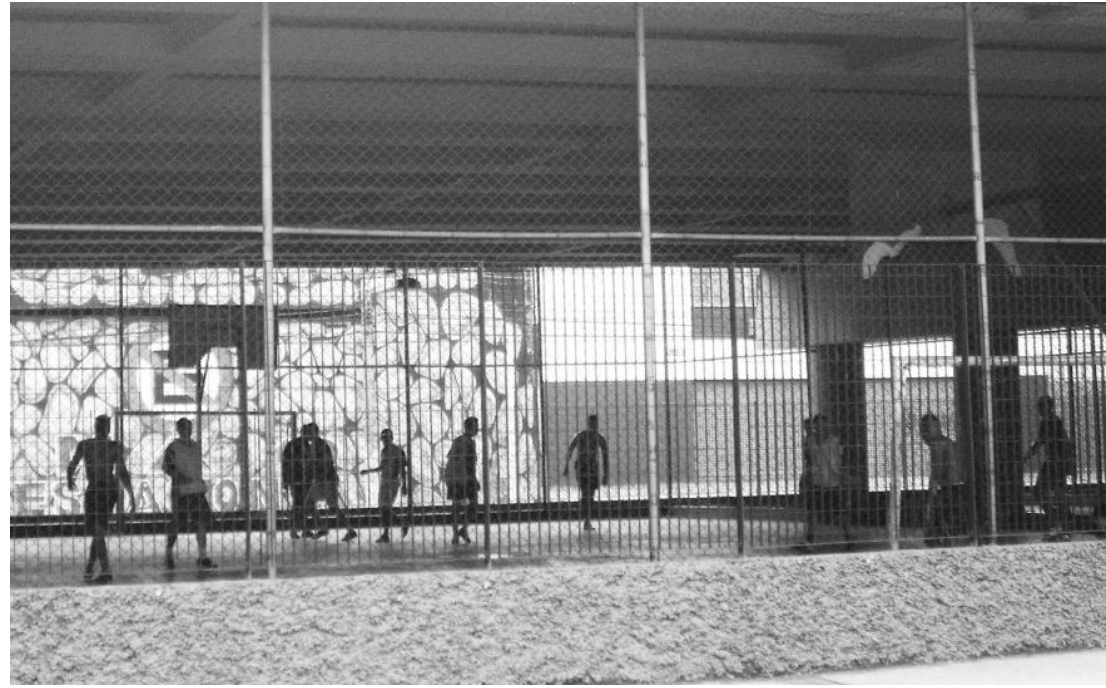

Fonte: Arquivo do autor, 2016.

A área poliesportiva não é frequentada apenas por quem utiliza as quadras. Os skatistas são um grupo presente, não é só pelo lugar ser um dos únicos na Zona Leste adequado para fazerem manobras com o skate que aqueles jovens estavam ali. Havia outras motivações, porém cada grupo fica no seu espaço: há pouca interação entre eles (Figura 7).

\footnotetext{
${ }^{11} \mathrm{O}$ espaço durante a semana só abre a partir das $14 \mathrm{~h}$ para a comunidade. 
Figura 7. Cartograma do uso da área poliesportiva no dia 10 de abril de 2016 às $15 \mathrm{~h}$.



Fonte: Arquivo do autor, 2016.

A diversidade de usuários quanto a gênero, idade, etnia e renda gera diferentes motivações para o uso da área poliesportiva. No entanto, não há um pensamento coletivo em relação a sua manutenção. Percebe-se que para esses grupos de skatistas, amigos, bolivianos, algo público é algo que pode ser usado sem impedimento e sem demandar uma responsabilização. É possível que esse pensamento decorra do fato de a área sempre ter apresentado uso após sua construção. Não houve necessidade de os usuários se apropriarem do espaço e trazerem para si a responsabilidade de sua utilização e gestão, como se vê ocorrer mais recentemente em outros espaços públicos da cidade.

\section{CONCLUSÃO}

Por meio deste estudo, buscando apresentar experiências de mobilização que já existe há décadas no baixio do viaduto Alcântara Machado, foi possível compreender a necessidade de uma combinação de usos, incluindo os mais banais, para contrapor um imaginário urbano no qual os baixios são espaços "residuais", "vazios", "marginais".

O estudo desse viaduto também nos mostra os pactos ilegais estabelecidos entre os atores sociais e os usuários a fim de alavancar recursos para a manutenção dos espaços no seu baixio e para que os seus efeitos virtuosos continuem a reverberar no bairro, como segurança na rua, oferta de lazer, encontro de imigrantes.

A mobilização dos atores sociais no viaduto Alcântara Machado reflete um princípio que tem pautado a administração pública contemporânea: a capacidade dos moradores de se mobilizar e organizar as suas demandas. Isso revela que esse processo não é tão novo, especialmente quando olhamos para outros territórios da cidade, fora do seu eixo tradicional de análise. No entanto, é necessário cautela na avaliação dessas experiências, pois tais atores são resistentes a deixar alguém propor atividades ou mudanças no espaço, e assim as iniciativas acabam geridas sob uma única visão: a sua.

\section{REFERÊNCIAS}

AGUIAR, Victor Martins de. Baixios de viadutos como desafio urbanístico: uma leitura das "terras de ninguém" nos viadutos Alcântara Machado e do Glicério. 2017. 167 f. Dissertação 
(Mestrado em Arquitetura e Urbanismo) - Faculdade de Arquitetura e Urbanismo, Universidade de São Paulo, São Paulo, 2017.

GROSTEIN, Marta Dora. Metrópole e expansão urbana: a persistência de processos "insustentáveis". São Paulo em Perspectiva, v. 15, n. 1, p. 13-19, 2001. https://doi.org/10.1590/S0102-88392001000100003

ROMAGNOLI, Roberta Carvalho. A cartografia e a relação pesquisa e vida. Revista Psicologia \& Sociedade, v. 21, n. 2, p. 166-173, 2009. https://doi.org/10.1590/S0102$\underline{71822009000200003}$

WINKIN, Yves. A nova comunicação: da teoria ao trabalho de campo. Campinas: Papirus, 1998. 